\title{
Avaliação de substratos para produção de mudas de alface
}

\author{
Paulo Espíndola Trani'; ${ }^{1}$ Deise Maria Feltrin²; Cristiano André Pott ${ }^{3}$; Márcio Schwingel ${ }^{4}$ \\ ${ }^{1}$ IAC, Centro de Horticultura, C. Postal 28, 13012-970 Campinas-SP; ${ }^{2}$ CEEPAR, 85045-720 Guarapuava-PR; ${ }^{3}$ UNICENTRO-CAA, \\ Depto. Agronomia, Centro Politécnico, 85040-080 Guarapuava-PR; ${ }^{4}$ Eng. Agrônomo Autônomo, C. Postal 28, 13012-970 Campinas-SP; \\ petrani@iac.sp.gov.br
}

\section{RESUMO}

Normalmente, os substratos disponíveis no mercado são recomendados indistintamente para grande número de culturas, sem considerar suas características e necessidades nutricionais na fase da formação de mudas. $\mathrm{O}$ experimento foi realizado em casa de vegetação, onde foram avaliados três substratos (Plantmax, Esfagno e GIII) para o desenvolvimento de mudas de alface cv. Regina. Foram realizadas as análises químicas e físicas de $\mathrm{pH}$, macronutrientes, sódio e micronutrientes, sendo calculadas a capacidade de troca catiônica (CTC) e a saturação por bases (V\%), além das análises de condutividade elétrica (CE), capacidade máxima de retenção de água (CRA) e granulometria dos substratos. A semeadura foi feita em bandejas de poliestireno expandido com 128 células cada. O delineamento utilizado foi de blocos ao acaso com três repetições. Foram avaliadas massa fresca da parte aérea e das raízes, massa seca da parte aérea e das raízes, número de folhas verdadeiras e altura média de plantas. Dentre os substratos avaliados, Plantmax demonstrou ser mais eficiente para produção de mudas de alface com melhor qualidade.

Palavras-chave: Lactuca sativa L., mudas de qualidade, hortaliça.

\begin{abstract}
Evaluation of substrates in the production of lettuce plantlets

Normally, the substrates available in the market are recommended indistinctly for a great number of crops, without taking into account its characteristics and nutritional requirements during the plantlet stage. The experiment was carried out in the greenhouse, where three different substrates (Plantmax, Sphagnum and G-III) were evaluated in the development of lettuce cv. Regina plantlets. Chemical and physical analysis such as $\mathrm{pH}$, macro and micronutrients and sodium, cation exchange capacity (CEC) and base saturation (V\%) were calculated as well as physical analysis such as electric conductivity, maximum water holding capacity and particle size of the substrates were carried out. The sowing was done in trays of expanded polystyrene with 128 cells each. We analyzed the fresh and dry mass of the aerial parts and of the roots, number of true leaves and mean height of the plantlets. Among the evaluated substrates, the Plantmax showed to be the most efficient in yielding lettuce plantlets with better quality.
\end{abstract}

Keywords: Lactuca sativa L., quality plantlets, vegetable.

(Recebido para publicação em 14 de março de 2006; aceito em 13 de maio de 2007)

A produção de mudas de qualidade é uma das etapas mais importantes no cultivo de hortaliças (Silva Júnior et al., 1995), pois delas depende o desempenho final das plantas nos canteiros de produção (Carmello, 1995). A utilização de recipientes com substratos em substituição ao uso de solo, na formação de mudas, tem proporcionado aumentos substanciais na qualidade das mesmas (Smiderle et al., 2001).

Menezes et al. (2000) consideram que pode ser vantajosa ao agricultor a formulação própria de substratos. Esses autores obtiveram melhores mudas de alface com a formulação própria, destacando-se o substrato obtido com 50\% de turfa e $50 \%$ de vermicomposto, este último material preparado com esterco de curral compostado com a minhoca vermelha da Califórnia, adicionando ao produto final $2 \mathrm{~g} / \mathrm{dm}^{3}$ da fórmula 5-2010. Todos os materiais preparados artesanalmente foram desinfetados. Considerando as dificuldades para o preparo de substratos homogêneos e o alto custo da mão de obra local, produtores de hortaliças da região de Campinas preferem adquirir os substratos produzidos por indústrias especializadas.

Um bom substrato não deve conter solo, devido à presença de fitopatógenos e sementes de plantas daninhas e por dificultar a retirada da muda com torrão (Filgueira, 2000). Suas características físicas, químicas e biológicas devem oferecer as melhores condições para que haja uma excelente germinação e favoreça o desenvolvimento das mudas (Gonçalves, 1994).

Segundo Schmitz et al. (2002), o pH, a capacidade de troca catiônica (CTC), a salinidade e o teor de matéria orgânica constituem as principais propriedades químicas consideradas na caracterização de substratos. Em relação às propriedades físicas, o autor destaca a densidade, a porosidade, o espaço de aeração e a economia hídrica (volumes de água disponíveis em diferentes potenciais).
Encontram-se no mercado substratos formulados pelos mais variados tipos de materiais quanto à origem de seus componentes ou composição das misturas. Isso ocorre porque as normas para produção e fiscalização de substratos no Brasil ainda não estão definidas (Fabri et al., 2004). Dentre 41 amostras de diferentes substratos comercializados na região de Piracicaba (SP), Fabri (2004) observou que apenas $19,5 \%$ apresentaram boa qualidade quanto às seguintes características físico-químicas: $\mathrm{pH}$, C.E., teores de macro e micronutrientes, aeração e retenção de umidade.

O objetivo do presente trabalho foi avaliar o efeito de três substratos comercializados na região de Campinas (SP), com base em análises físico-químicas, no desenvolvimento de mudas de alface.

\section{MATERIAL E MÉTODOS}

O experimento foi desenvolvido em casa de vegetação localizada no Centro 
Experimental de Campinas do Instituto Agronômico /APTA/SAA, de julho a agosto de 2004.

O delineamento utilizado foi de blocos ao acaso com 3 tratamentos e 3 repetições. Os tratamentos consistiram de três substratos comerciais: Plantmax PXHA (Eucatex), Esfagno (Sarrua) e G-III (Gioplanta). Os substratos Plantmax, e G-III, tendo como principais componentes a casca de pinus carbonizada e vermiculita, são bastante difundidos entre produtores de mudas de hortaliças na região de Campinas (SP). O produto Esfagno importado do Canadá pode se constituir como mais uma opção para produção de mudas de hortaliças.

As plântulas foram irrigadas por microaspersão, com 2 aspersores por $\mathrm{m}^{2}$ e freqüência de 4 aplicações por dia, procurando manter-se as tensões de água no substrato sempre próximas a capacidade de vaso e a saturação máxima de modo a satisfazer as necessidades hídricas da cultura nesse estágio evitando-se qualquer déficit hídrico. Foram realizadas análises físico-químicas desses substratos sendo determinados os teores de matéria orgânica, nitrogênio e a relação Carbono/Nitrogênio $(\mathrm{C} / \mathrm{N})$ adotando-se a metodologia recomendada por Alcarde (1982) para análise de fertilizantes minerais e a metodologia de análise para adubos orgânicos preconizada por Kiehl (1985). Foram também determinados o $\mathrm{pH}, \mathrm{P}, \mathrm{K}, \mathrm{Ca}, \mathrm{Mg}$, $\mathrm{H}, \mathrm{S}, \mathrm{Na}, \mathrm{Fe}, \mathrm{Mn}, \mathrm{Cu}, \mathrm{Zn}$ e B, além do cálculo da CTC e V\%, adotando-se a metodologia recomendada por Raij \& Quaggio (1983) para análise química de solo. Foi também realizada análise específica para substratos atualmente adotada pelo Instituto Agronômico de Campinas a partir de metodologia descrita em Abreu et al. (2002). Com a adoção dessas duas metodologias para as determinações químicas (a recomendada por Raij \& Quaggio e a descrita em Abreu et al., 2002), é possível uma interpretação mais abrangente dos resultados. A metodologia utilizada pelo IAC para substratos consiste em uma adaptação de método empregado na Holanda e a metodologia tradicional de análise de solo continua sendo satisfatória para a interpretação de diversas características físico-químicas de substratos.

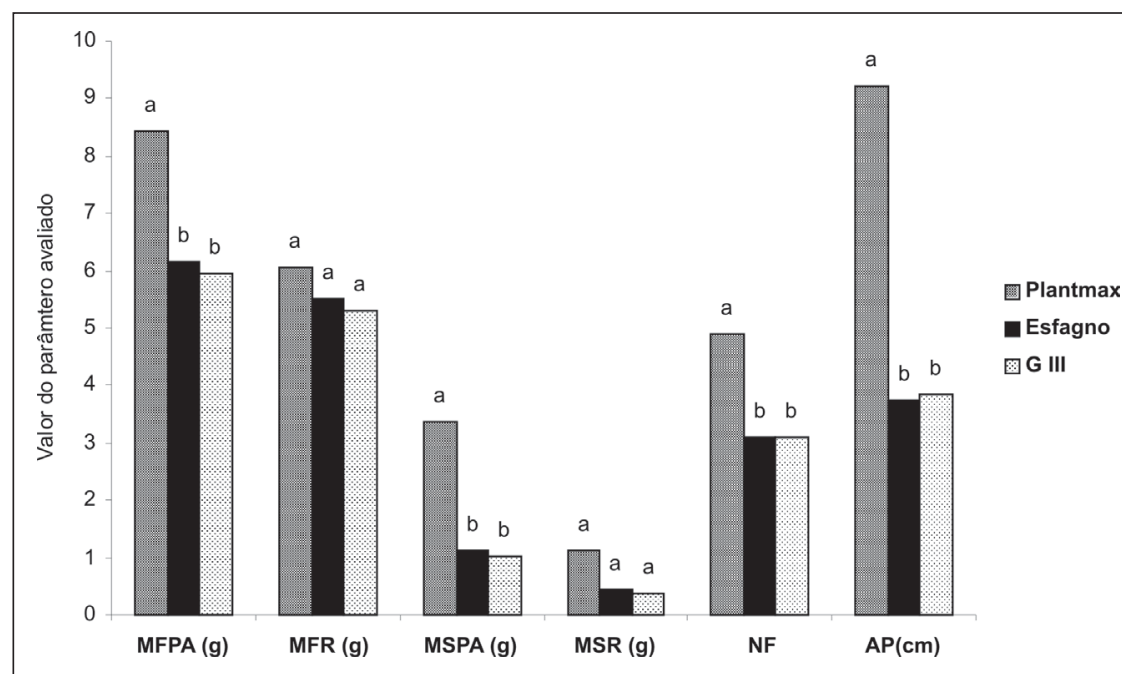

*Médias seguidas pela mesma letra não diferem entre si pelo teste de Tukey $(p=0,05)$ (Means followed by the same letter are not significantly different by Tukey test $(p=0,05))$.

Figura 1. Massa fresca da parte aérea (MFPA), massa fresca das raízes (MFR), massa seca da parte aérea (MSPA), massa seca das raízes (MSR); número de folhas verdadeiras (NF) e altura da planta (AP) de mudas de alface cv. Regina, cultivadas em três diferentes substratos, aos 23 dias após emergência (Fresh mass of aerial part (MFPA), fresh mass of root (MFR), dry mass of aerial part (MSPA), dry mass of root (MSR); number of true leaves (NF) and height of lettuce plantlets (AP), cv. Regina, cultivated in three different substrates, 23 days after emergency). Campinas, IAC, 2004.

Determinou-se a granulometria dos substratos em seis peneiras "Tyler" de malhas (mesh) 8 (malha com espaçamento de $2,38 \mathrm{~mm}) ; 10$ (2,00 $\mathrm{mm}) ; 20$ (0,84 mm); 35 (0,42 mm); 48 $(0,30 \mathrm{~mm})$ e $60(0,25 \mathrm{~mm})$ utilizadas para avaliação de corretivos da acidez do solo e, também, a capacidade máxima de retenção de água (CRA) dos substratos em questão.

A semeadura da alface 'Regina' foi realizada em 13/07/04 em bandejas de poliestireno expandindo com 128 células cada, sendo adicionadas 3 sementes nuas por célula, efetuando-se o desbaste uma semana após a emergência, deixando-se uma planta por célula.

Para avaliação do desenvolvimento das mudas, realizado 23 dias após a emergência, utilizou-se das características: massa fresca da parte aérea (MFPA), massa fresca das raízes (MFR), massa seca da aérea (MSPA), massa seca das raízes (MSR), número de folhas verdadeiras (NF) e altura média das plantas (AP), determinada a partir da base do caule (colo) até o ápice da folha mais nova. A parte aérea e as raízes foram acondicionadas separadamente em sacos de papel e mantidos em estufa a $70^{\circ} \mathrm{C}$, para determinação da MSPA e
MSR. Os dados obtidos foram submetidos à análise de variância, e as médias comparadas pelo teste de Tukey $(\mathrm{p}=0,05)$.

\section{RESULTADOS E DISCUSSÃO}

Houve maior eficiência do substrato Plantmax na produção de mudas de alface (Figura 1), diferenciando-se dos outros substratos quanto ao número de folhas verdadeiras, e altura média de planta, massa fresca e massa seca da parte aérea.

Dos parâmetros avaliados, apenas aqueles relacionados ao desenvolvimento radicular (MFR e MSR) não apresentaram diferenças estatisticamente significantes, ou seja, eventuais variações, tanto dos aspectos físicos (como aeração ou impedância mecânica, por exemplo) quanto dos aspectos químicos dos substratos, não sendo suficientes para interferir no desenvolvimento das raízes das plântulas durante este estágio de cultivo.

O substrato Plantmax tem demonstrado ser eficiente para produção de algumas espécies de hortaliças como o pimentão (Capsicum annuиm) segundo Silva (1994), que observou superiorida- 
Tabela 1. Análise química de três substratos agrícolas (capacidade máxima de retenção de água (CRA máx), pH, macronutrientes, CTC, $\mathrm{V} \%, \mathrm{C} / \mathrm{N}, \mathrm{Na}^{1}$ e micronutrientes ${ }^{1}$ ), conforme metodologia adotada para análise de solo (Chemical analysis of three agricultural substrates (maximum water holding capacity (CRA max), $\mathrm{pH}$, macronutrients, $\mathrm{CEC}(\mathrm{CTC}), \mathrm{V} \%, \mathrm{C} / \mathrm{N}, \mathrm{Na}^{1}$ and micronutrients ${ }^{1}$ ), according to methodology adopted for soil analysis). Campinas, IAC, 2004.

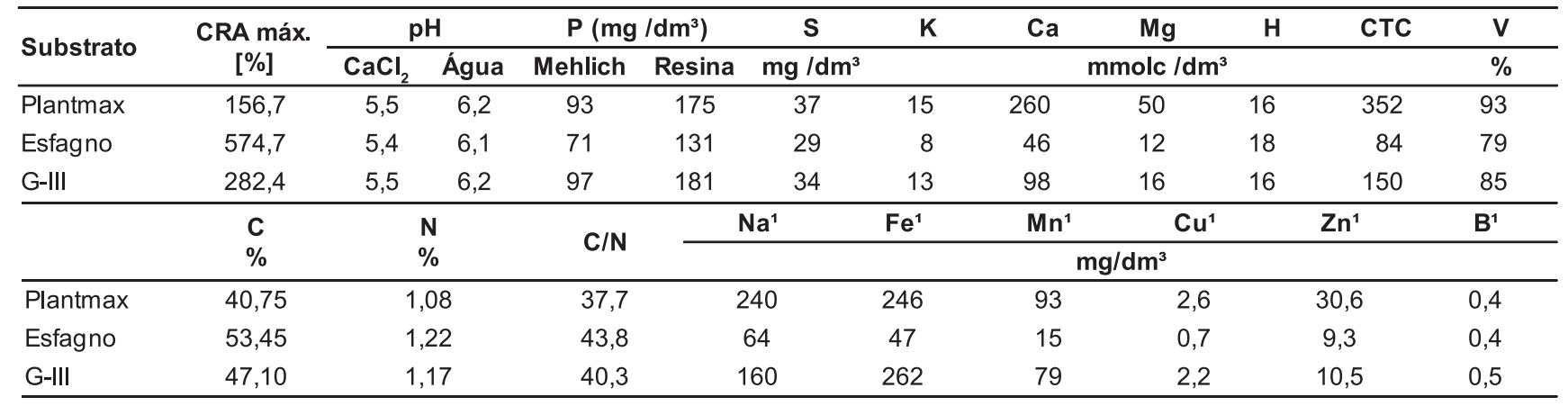

${ }^{1}$ Extrator Mehlich (Mehlich extractant)

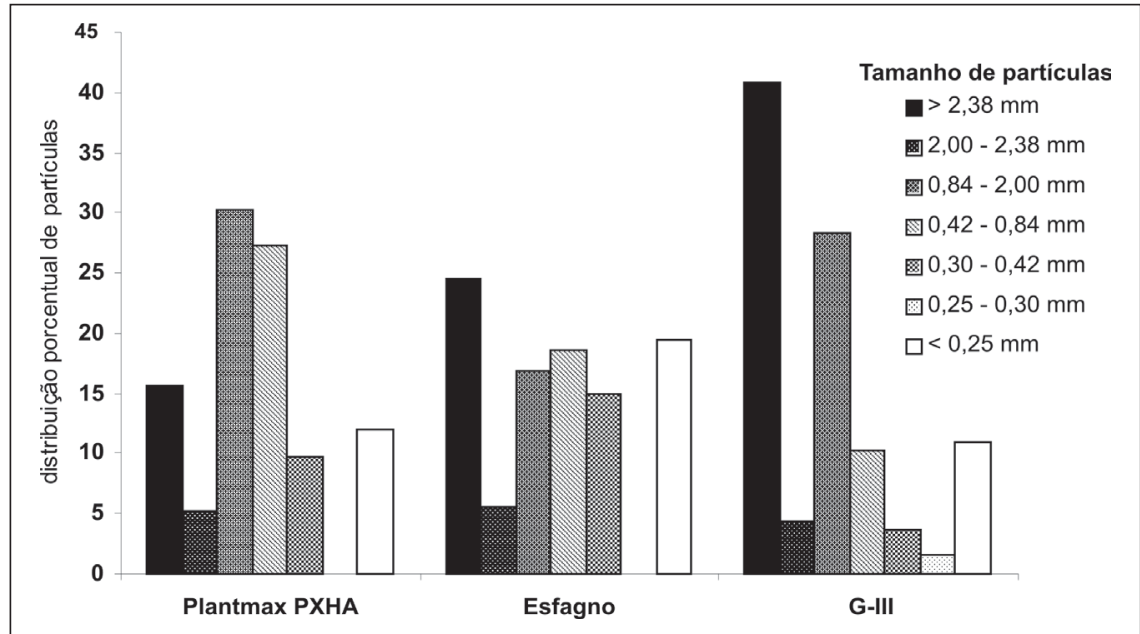

Figura 2. Distribuição porcentual das partículas dos substratos conforme tamanho (abertura das malhas das peneiras) (Percentual distribution of substrate particles by the size (sieve granulometry)). Campinas, IAC, 2004.

de deste substrato para produção de mudas de pimentão, inclusive quanto ao acúmulo de macronutrientes na parte aérea das mudas. Braz et al. (1996) também relataram, para a mesma hortaliça melhor incremento da matéria seca das plântulas com o emprego deste substrato.

Semelhantemente, Luz et al. (2000) observaram para o Plantmax maior massa seca da parte aérea e de raízes em tomate (Lycopersicon esculentum).

Em experimento com alface crespa (cv. Vera), Trani et al. (2004), igualmente observaram melhores resultados com Plantmax HA frente aos três outros substratos avaliados (Hortimix folhosas, Golden Mix47 e Vida Verde Tropstrato Hortaliças), quanto à altura de planta e número de folhas. Aos 15 dias, mudas cultivadas em Plantmax já atingiram altura superior a $5 \mathrm{~cm}$, mínima necessária para o transplante aos 20-25 dias. Após dez dias, os autores confirmaram interferência do substrato no número de folhas, tal que aos 20 dias o Plantmax proporcionou maior número de folhas do que os demais substratos.

Avaliando a eficiência do substrato Plantmax e sua combinação com solo e areia em experimento de produção de mudas de alface, pepino e pimentão, Smiderle et al. (2001) obtiveram os melhores resultados com o substrato puro. Não obstante ser o tratamento que demonstrou menor índice de velocidade de emergência de plântulas de alface e pepino, Plantmax não combinado proporcionou maior altura de plântulas às três culturas, além da maior produção de matéria seca de plântulas e raízes de alface e de pimentão.

Por outro lado, Carneiro Jr. et al. (2000), também em ensaio com pepino, não detectaram influência do tipo de substrato na massa seca da parte aérea e no número de frutos. Menezes et al. (2000) verificaram que o Plantmax (sem especificar o tipo) foi inferior a outros substratos quanto à produção de matéria seca (parte aérea e raízes) e número de folhas definitivas da alface (cv. Monalisa). Tem sido constatado em período recente em Campinas por produtores de mudas de hortaliças certa desuniformidade neste substrato, além da compostagem imperfeita da casca de pinus, ocasionando, por vezes, problemas no desenvolvimento das mudas.

Minami (1995) observa quanto às características físicas, que o substrato deve apresentar baixa porosidade, isenção de contaminações fitopatogênicas e baixo custo. Andrade Júnior et al. (1997) e Silva \& Marouelli (1998) mostram que as tensões entre 10,0 e $38,2 \mathrm{kPa}$ (ou seja, próximos à capacidade de campo) a 15 $\mathrm{cm}$ de profundidade propiciam os melhores resultados produtivos para hortaliças em sistema de cultivo protegido no solo. Menezes et al (2000) verificaram diferenças significativas entre as propriedades físicas dos substratos avaliados, inclusive quanto à distribuição do tamanho das partículas dos materiais puros, substratos comerciais e formulados para produção de mudas de alface.

Fernandes e Corá (2001) realizando análise física do substrato comercial puro e em mistura com outros materiais 
Tabela 2. Resultados de análise química de três substratos agrícolas segundo metodologia específica para substratos, adotada pelo Instituto Agronômico de Campinas (pH, CE, Na, macro e micronutrientes) (Chemical analysis of three plant substrates according to substrates specific methodology, adopted by the Instituto Agronômico de Campinas (pH, electric conductivity (CE), Na, macro and micronutrients)). Campinas, IAC, 2004.

\begin{tabular}{|c|c|c|c|c|c|c|c|c|c|c|c|c|c|c|c|c|}
\hline \multirow{2}{*}{ Substrato } & \multirow{2}{*}{$\mathrm{pH}$} & CE & $\mathrm{N}-\mathrm{NO}_{3}$ & $\mathbf{P}$ & $\mathrm{Cl}$ & $s$ & $\mathrm{~N}-\mathrm{NH}_{4}$ & $K$ & $\mathrm{Na}$ & $\mathrm{Ca}$ & $\mathrm{Mg}$ & B & $\mathrm{Cu}$ & $\mathrm{Fe}$ & $M n$ & $\mathrm{Zn}$ \\
\hline & & $\mathrm{dSm}^{-1}$ & \multicolumn{14}{|c|}{$\mathrm{mg} / \mathrm{dm}^{3}$} \\
\hline Plantmax & 4,2 & 3,0 & 72 & 11 & 200 & 560 & 4,7 & 156 & 32 & 234 & 193 & 0,2 & 0,1 & 0,2 & 0,3 & 0,1 \\
\hline Esfagno & 5,5 & 2,1 & 67 & 38 & 33 & 190 & 2,8 & 177 & 16 & 135 & 120 & 0,1 & 0,1 & 0,1 & 0,1 & 0,1 \\
\hline G-III & 4,1 & 2,5 & 0 & 8 & 500 & 135 & 2,2 & 275 & 172 & 29 & 43 & 0,2 & 0,1 & 1,1 & 0,1 & 0,1 \\
\hline
\end{tabular}

Método de extração: 1:1,5 (Holanda). Métodos de determinação: N-(amoniacal e nitrato): destilação; K, Ca, Mg, P, S, Cu, Fe, Mn, Zn: ICPOES; C-orgânico: Walkley-Black; Nitrogênio Total: Kjeldahl (Extraction method: 1:1,5 (Holand). Determination methods: Amoniacal and nitrate $-\mathrm{N}$ ): destilation: $\mathrm{K}, \mathrm{Ca}, \mathrm{Mg}, \mathrm{P}, \mathrm{S}, \mathrm{Cu}, \mathrm{Fe}, \mathrm{Mn}, \mathrm{Zn}$ : ICP-OES; Organic-C: Walkley-Black; Total N: Kjeldahl).

(composto orgânico, casca de arroz carbonizada e húmus de minhoca), observaram que o húmus de minhoca foi o que mais contribuiu para elevar a macroporosidade, favorecendo a aeração do substrato. O substrato comercial puro (não foi especificado qual o tipo) teve como característica maior microporosidade o que auxilia a retenção da água de irrigação. Drzal et al. (1999) e Schmitz et al. (2002) afirmam que o conteúdo de água retido no substrato é diretamente correlacionado com a distribuição dos poros por tamanho. Segundo o primeiro autor, os macroporos não retêm água sob força gravitacional, sendo estes, por conseguinte, responsáveis pela aeração das raízes. Ballester-Olmos (1992) explica que são os microporos aqueles responsáveis pela retenção de água.

Levando-se em consideração que a repartição dos poros está diretamente associada à distribuição granulométrica (Ferraz et al., 2005), pode-se inferir, através da análise de granulometria, a respeito das diferenças obtidas nos resultados concernentes à capacidade de retenção de água (CRA). Conforme Substratos (2001), a granulometria dos substratos inorgânicos à base de areia lavada deve situar-se entre 0,05 e 2,0 $\mathrm{mm}$. A Figura 2 mostra que os três substratos avaliados neste trabalho continham a maior parte das partículas nessa faixa de tamanho. Através da Tabela 1, pôde-se observar, porém, que o Esfagno obteve o maior valor de CRA. Isto se deve, de acordo com explicação de Ferraz et al. (2005), à maior proporção de partículas finas (observar duas últimas partições granulométricas com partículas menores que $0,30 \mathrm{~mm}$ ), as quais se arranjam entre as mais grossas formando poros de menor diâmetro, elevando assim a CRA. Esse fato também pode explicar a menor CRA do Plantmax, pela razão inversa.

Embora, conforme já mencionado, os parâmetros relativos ao desenvolvimento radicular não demonstrem variações entre os tratamentos, sendo a aeração decorrente da presença de macroporos, é possível levantar a hipótese de que, uma vez tendo o substrato Plantmax menor CRA, portanto menor proporção de microporos em relação a macroporos, este detém a maior aeração. Isto também deve ser considerado para explicar as divergências nos demais parâmetros. Cabe lembrar que a aeração é essencial para a respiração das células radiculares e, portanto, para o desempenho das plantas em geral.

A Tabela 1 mostra as análises de matéria orgânica, nitrogênio total e relação $\mathrm{C} / \mathrm{N}$ dos substratos avaliados. Baseando-se em Verdonck et al. (1981) e Penningsfeld (1983), os quais estabeleceram o valor mínimo de $50 \%$ de matéria orgânica para substratos, Schmitz et al. (2002) estimam que os teores de carbono orgânico para substratos devem se situar acima de $25 \%$. Os substratos avaliados no presente estudo satisfazem estes critérios.

Segundo Substratos (2001), os compostos orgânicos destinados à fabricação de substratos devem ter inicialmente relação C/N de 30/1 a 40/1. Observando-se a Tabela 1 não foi possível, pelos parâmetros apresentados explicar as diferenças verificadas na produção de mudas de alface.

A Tabela 1 mostra ainda o $\mathrm{pH}$, os teores de macronutrientes, sódio, capacidade de troca catiônica (CTC), satu- ração por bases (V\%) e micronutrientes dos substratos analisados adotando-se a metodologia para análise de solo atualmente adotada pelo IAC, descrita em Raij \& Quaggio (1983).

Observando a faixa de $\mathrm{pH}$ (em água) na qual há maior disponibilidade de nutrientes, Kämpf (2000) considera um valor ideal situado entre 5,2 e 5,5 para substratos de base orgânica e entre 6 e 7 para aqueles de base mineral. Levandose em conta os substratos avaliados constituírem-se preponderantemente de material orgânico, através da Tabela 1 pode-se verificar que todos os substratos estão acima e próximos da faixa de $\mathrm{pH}$ ideal para o respectivo material. Ressalte-se que as pequenas diferenças entre os valores alcançados pelos substratos não justificam as discrepâncias na resposta produtiva obtida ao final do ensaio.

Com relação à CTC, o Esfagno foi o único dos substratos estudados a apresentar valor abaixo da faixa ideal de 120 $\mathrm{mmol} / \mathrm{dm}^{3}$ estabelecida por Penningsfeld (1983) para o cultivo em recipientes, com abastecimento esporádico de nutrientes. Destaca-se a maior CTC apresentada pelo substrato Plantmax, bem como os maiores teores de cálcio e magnésio em relação aos outros substratos, o que permite explicar, em parte, o melhor desempenho deste substrato em relação aos demais. Destacouse também o maior teor de zinco do Plantmax $\left(30,6 \mathrm{mg} / \mathrm{dm}^{3}\right)$, três vezes superior aos teores dos outros dois substratos.

A Tabela 2 corresponde às análises químicas dos substratos conforme a metodologia adotada pelo IAC a qual vem sendo atualmente utilizada na rotina de análises de substratos por esta Instituição Científica. Quando confrontada com a Ta- 
bela 1 , evidenciam-se ainda mais as preponderantes concentrações de $\mathrm{Ca}$ e $\mathrm{Mg}$ no substrato Plantmax em relação aos demais substratos avaliados. Através desta análise também se destaca neste mesmo substrato, teor de enxofre de três e quatro vezes superior ao substrato G-III e ao Esfagno, respectivamente. Isto deve ser levado em consideração para se explicar os melhores resultados atingidos pelo Plantmax.

Maas (1984) e Ayers \& Westcot (1991), citados por Viana et al. (2001), mencionam ser a alface "moderadamente sensível" à salinidade, sofrendo a produção um decréscimo de $13 \%$ a cada aumento unitário de condutividade elétrica (CE) do extrato de saturação acima de $1,3 \mathrm{dSm}^{-1}$. Andriolo et al. (2005) observaram redução no crescimento e na produção de massa fresca de plantas de alface cv. Vera quando os níveis de salinidade foram superiores a 2,0 e 2,6 $\mathrm{dSm}^{-1}$, respectivamente. Tais plantas foram cultivadas em areia e fertirrigadas com solução nutritiva. As mudas de alface neste experimento desenvolvidas nos substratos Esfagno, GIII e Plantmax com CE de 2,1; 2,5 e $3,0 \mathrm{dSm}^{-1}$, respectivamente, não apresentaram sintomas de crestamento de folhas provavelmente devido ao efeito tampão destes substratos. Fabri (2004) observou que mudas de alface desenvolveramse melhor nos substratos constituídos de adubo de curral e húmus apresentando condutividade elétrica de 3,73 e 4,87 $\mathrm{dSm}^{-1}$, respectivamente. Provavelmente o poder tampão do material orgânico tem influência sobre a ação dos sais que podem prejudicar a germinação e o desenvolvimento das plântulas. Isto demonstra a importância no monitoramento constante dos materiais utilizados na formulação de substratos além da qualidade da água de irrigação.

Nas condições deste experimento pode-se concluir que o substrato Plantmax PXHA foi superior aos outros dois materiais, para obtenção de mudas de alface destinadas ao cultivo comercial devido a algumas características químicas e nutricionais, como maiores teores de $\mathrm{Ca}$, $\mathrm{Mg}, \mathrm{S}$ e elevada CTC frente aos demais substratos avaliados. Quanto aos atributos físicos, pode-se considerar que a aeração provavelmente colaborou para melhor rendimento do referido substrato.

\section{AGRADECIMENTOS}

Os autores agradecem ao laboratório LAGRO de Campinas (SP) e ao La- boratório de Fertilidade do Solo do Instituto Agronômico de Campinas pela realização das análises físico-químicas dos substratos.

\section{REFERÊNCIAS}

ABREU MF; ABREU CA; BATAGLIA OC. 2002. Uso da análise química na avaliação da qualidade de substratos e componentes. In: ENCONTRO NACIONAL DE SUBSTRATOS PARA PLANTAS, 3, Campinas, 2002. Campinas: IAC, p. 17-28 (IAC. Documentos, 70).

ALCARDE JC. 1982. Métodos simplificados de análise de fertilizantes minerais (NPK). Brasília: Laboratório Nacional de Referência Vegetal, $49 \mathrm{p}$.

ANDRADE JÚNIOR AS; KLAR AE. 1997. Manejo da irrigação da cultura da alface (Lactuca sativa L.) através do tanque classe A. Scientia agricola 54: 31-38.

ANDRIOLO JL; LUZ GL; WITTER MH; GODOI RS; BARROS GT; BORTOLOTTO, OC. 2005. Growth and yield of lettuce plants under salinity. Horticultura Brasileira 23: 931934.

BALLESTER-OLMOS JF.1992. Substratos para el cultivo de plantas ornamentals. Valencia: Instituto Valenciano de Investigationes Agrarias, Hojas Divulgadoras, 11, $44 \mathrm{p}$.

BRAZ LT; SILVA MRL; CASTELLANE PD. 1996. Efeito de diferentes substratos na formação de mudas de pimentão. Horticultura Brasileira 14: 75.

CARMELLO QAC. 1995. Nutrição e adubação de plantas hortícolas. In: MINAMI K. Produção de mudas de alta qualidade em horticultura. São Paulo: T. A. Queiroz, p. 27-37.

CARNEIRO JÚNIOR AG; SENO S; FERREIRA FILHO HF. 2000. Avaliação de cinco diferentes substratos para o cultivo de pepino fora do solo. Horticultura Brasileira 18, suplemento, p. 494-495.

DRZAL MS; FONTENO WC; CASSEL DK. 1999. Pore fraction analysis: a new tool for substrate testing. Acta Horticulture 148: 43-53.

FABRI EG. 2004. Determinação da qualidade dos substratos comercializados em Piracicaba SP. Piracicaba:USP-ESALQ. 88 p (Tese mestrado).

FABRI EG; SALA FC; MINAMI K. 2004. Caracterização física e química de diferentes substratos. In: BARBOSA JG; MARTINEZ HEP; PEDROSA MW; SEDIYAMA MAN (Ed.). Nutrição e adubação de plantas cultivadas em substratos. Viçosa: UFV, p.318.

FERNANDES C; CORÁ JE. 2001. Substratos hortícolas. Cultivar HF 10: 32-34.

FERRAZ MV; CENTURION JF; BEUTLER AN. 2005. Caracterização física e química de alguns substratos comerciais. Acta Scientia Agronomica 27: 209-214.

FILGUEIRA FAR. 2000. Novo Manual de Olericultura. Viçosa: UFV. 402p.

GONÇALVES AL. 1994. Substratos para produção de mudas ornamentais. In: MINAMI K: TESSARIOLI NETO J; PENTEADO SR; SCARPARE FILHO JA. Produção de mudas hortícolas de alta qualidade. Piracicaba: ESALQ/SEBRAE, 156p.
KÄMPF AN. 2000. Seleção de materiais para uso como substrato. In: KÄMPF NA; FERMINO MH. (Eds.) Substratos para plantas: a base da produção vegetal em recipientes. Porto Alegre: Gênesis, p.139-145.

KIEHL EJ. 1985. Fertilizantes orgânicos: determinações analíticas. Piracicaba, Editora Agronômica “Ceres" Ltda., p. 414-436.

LUZ JMQ; PAULA EC; GUIMARÃES TG. 2000. Produção de mudas de alface, tomateiro e couve-flor em diferentes substratos comerciais. Horticultura Brasileira 18, suplemento, p. 579-581.

MENEZES JÚNIOR FOG; FERNANDES HS; MAUCH CR; SILVA JB. 2000. Caracterização de diferentes substratos e seu desempenho na produção de mudas de alface em ambiente protegido. Horticultura Brasileira 18: 164-170.

MINAMI K. 1995. Produção de mudas de hortaliças de alta qualidade em horticultura. São Paulo: TA Queiroz. 128p.

PENNINGSFELD F. 1983. Kultursubstrate für den Gartenbau, besonders in Deutschland: ein kritischer Überblick. Plant and Soil 75: 269-281.

RAIJ B; QUAGGIO JA. 1983. Métodos de análise de solo para fins de fertilidade. Campinas: Instituto Agronômico, 31 p. (IAC. Boletim Técnico, 81).

SANTOS SR; PEREIRA GM. 2004. Comportamento da alface tipo americana sob diferentes tensões de água no solo, em ambiente protegido. Engenharia Agricola 24: 569-577.

SCHMITZ JAK; SOUZA PVD; KÄMPF AN. 2002. Propriedades químicas e físicas de substratos de origem mineral e orgânica para o cultivo de mudas em recipientes. Ciência Rural 32: 937-944.

SILVA MRL. 1994. Efeito de diferentes substratos na formação de mudas de pimentão (Capsicum annuum L.) em bandejas de poliestereno expandido. Jabotical: UNESP-FCAV. 75 p. (Graduação em agronomia).

SILVA WLC; MAROUELLI WA. 1997. Manejo da irrigação em hortaliças no campo e em ambientes protegidos. In: FARIA MA; SILVA EL; VILELA LAA; SILVA AM. (Ed.). Manejo de irrigação. Poços de Caldas: UFLA/ SBEA, p. 311-348.

SILVA JÚNIOR, AA; MACEDO SG; STUKER H. 1995. Utilização de esterco de peru na produção de mudas de tomateiro. Florianópolis: EPAGRI, (Boletim Técnico 73), 28 p.

SMIDERLE OJ; SALIBE AB; HAYASHI AH; MINAMI K. 2001. Produção de mudas de alface, pepino e pimentão em substratos combinando areia, solo e Plantmax®. Horticultura Brasileira 19: 253-257.

SUBSTRATOS y nutrición artificial. 2001. New York, Agricultura de las Americas 50: 24-27.

TRANI PE; NOVO MCSS; CAVALLARO JÚNIOR ML; TELLES LMG. 2004. Produção de mudas de alface em bandejas e substratos comerciais. Horticultura Brasileira 22: 290-294.

VERDONCK O; VLEESCHAUMER D; DE BOODT M. 1981. The influence of the substrate to plant growth. Acta Horticulturae 150: 467-473.

VIANA SBA; FERNANDES PD; GHEYI HR. 2001. Germinação e formação de mudas de alface em diferentes níveis de salinidade de água. Revista Brasileira de Engenharia Agrícola e Ambiental 5: 259-264. 